\title{
Imaginative communities and place branding
}

\author{
Robert Govers $^{1}$
}

Published online: 16 September 2019

(c) Springer Nature Limited 2019

One of the challenges for place branding and public diplomacy is that they are concepts that are often ignored and misunderstood by those who should take most interest. Strategic reputation management that is not supported by senior government is doomed to fail, yet place branding and public diplomacy are often brushed aside by cabinets and councils as tools to be dealt with solely by communications departments or marketing organisations. By using marketing, communications, PR and branding concepts and terminologies in our discipline, we sometimes seem to shoot ourselves in the foot. In 2018, I therefore published a little book entitled Imaginative Communities. It is an attempt to present the topic of place reputation management in a way that is accessible to all and to avoid being categorised a priori as a largely irrelevant policy add-on. The book shuns the use of jargon, metaphors or concepts that are supposedly understood, but often are not. It is only at the end of the book, in the last chapter, that I elaborate on the conceptual link between imaginative communities, place marketing and place branding. I would like to share these insights and their implications for our field of study in this editorial, but not before explaining why the book is entitled Imaginative Communities.

The book is about communities, as I think that the reputation of a place is built by the people who feel connected to that place and it starts with understanding the shared sense of identity, belonging and purpose. The book is about communities doing imaginative things, because I think that reputations are built by creating relevant buzz, which is done by reinforcing and showcasing identity in original, creative, innovative, captivating and inspiring initiatives that show the world what the community is about in order to build a distinctive, relevant, authentic, consistent and memorable reputation. Imaginative initiatives that such communities develop can be policies, infrastructures, projects, investments or

Robert Govers

rgovers@rgovers.com

1 Antwerp, Belgium events. Some examples of imaginative community initiatives, as I describe them in my book, are as follows:

- Estonia adapting its constitution to include internet access as a human right and allowing e-residency, to emphasise the country's tech-savvy nature compared to other countries in the Baltic region.

- Bhutan, a country where well-being has long been prioritised over material gain, inventing and institutionalising the idea of gross national happiness.

- Dubai's man-made islands in the shape of palm trees, which traditionally represent the source of life in the region around the Arabian Gulf.

- The Hague, international city of peace and justice, creating the peace festival and cyber-security delta.

- Austin's South by Southwest (SXSW) Festival as a celebration of the city's musical roots.

- Migrants and refugees building their genuine "land of the free": the United States of America.

- The Dutch city of Den Bosch mobilising everything and everyone in 2016 to commemorate the death of Hieronymus Bosch, one of the most influential Dutch Masters of all time, who died in 1516 in the city that gave him his name.

- The pyramids and the Forum as representations of Egyptian and Roman cultural identity, religion and scientific achievements of their time.

- Oslo's Future Library, where a thousand trees have been planted just outside the city to supply paper for a special anthology of books to be printed in one hundred years' time. In the meantime, each year one author contributes a manuscript, which is held in a trust, unpublished, until 2114 , to reflect the city's forward-looking mentality and mantra that the best is yet to come.

- Finland creating its own set of emoticons to express emotional aspects of Finnishness on social media and on mobile devices anywhere in the world, reflecting the tech-savvy and quirky, fun-loving nature of the Finns.

- The House of Medici building the home of the Renaissance in Florence, with the Duomo di Firenze (Cattedrale 
di Santa Maria del Fiore) as one of the first examples of captivating iconic masterpiece structures built to attract visitors to the city state.

- Gaudí's Barcelona or Manrique's Lanzarote.

- The Dutch province of Limburg - a region that, over the course of its history, has learned to live with nearby and shifting international borders-organising cross-border design, arts and sports projects.

- The Van Gogh-inspired "starry night" cycle path in Eindhoven, the city of lights in the Netherlands. The path is paved with fluorescent stones that light up at night to resemble the painting by Van Gogh, who lived in the area.

Now, how should imaginative communities de-market and re-brand the practice of place branding (based on Imaginative Communities' chapter 8) and what does it all imply?

\section{The need to de-market}

Marketing has become such a dominant force in modern society that one would think that the concept barely requires explanation. It should be hardly a secret that it is driven by understanding and satisfying market demands. Yet, unfortunately, marketing remains misunderstood by many as just being about promotion. Being much more than that, marketing processes are built around knowing one's (potential) customers, researching their needs and wants, and segmenting the market so as to target the right people. Products and services are then designed, promoted and distributed in such a way as to acquire unique positioning in the minds of those target audiences. It is also referred to as "customer focus".

Popular wisdom suggests that even communities need to market themselves, promote the country, sell the city. I wonder if that is very pertinent and whether customerdriven community engagement is appropriate. Communities are not for sale and the economic dimension is only one perspective. Sure, people need to work, earn a living and finance their future and that of their offspring, but they are also concerned about their health, friendships, environment and cultural identity. Reducing communities to marketable products, therefore, seems inappropriate. What is more, the marketing perspective seems to suggest that the focus needs to be on how we serve market demands. Even if residents are seen as an internal market, is that an appropriate prioritisation of policy agendas? Are non-commercial priorities of well-being, sustainability or social inclusion not just as important if not more so? There are modern interpretations of marketing that include an appreciation of these collective demands and maybe my issue is more with commoditisation than with community marketing per se; yet, the practice of it seems to be rather old-fashioned.
Also, of course, one of the essential ways in which communities prosper is to engage in economic exchange with the outside world. Trading and export of commodities, products and services is the most obvious way in which communities earn an income, and it has been an essential part of the economic development of communities for millennia. More recently, the importance of attracting tourists, international students and migrant workers has risen up the policy agenda. In addition, of course, creating investment opportunities and facilitating desirable factor conditions aims to attract foreign direct investment.

All these economic domains, however, have their specialised and legitimate professional organisations: tourism management organisations, investment promotion agencies, export marketing associations and talent attraction agencies. It is perfectly logical that communities set up agencies that segment tourism, investment and export markets in order to position and promote community offerings effectively and efficiently among the right audience. Using promotional tools such as advertising, special offers, direct marketing or public relations under these circumstances is fine, as one is presumably communicating with an audience that is interested in the offer and welcomes the attention (assuming skilful market research, targeting and positioning).

That, obviously, is something completely different from promoting the country or selling the city. Tourism and export marketing, investment promotion and talent attraction are about marketing a product to a target audience, not about community boosterism. The confusion is probably caused by the fact that selling a tourism product, an export product or an investment opportunity is much easier for communities that have a strong reputation. Communities that are unknown or unpopular internationally will find it much harder and more expensive to market their offerings. This has been proven over and over again in studies on destination image (tourism marketing research), country-of-origin effects (export marketing research) or location attractiveness (investment decision research).

So marketing requires reputation, which does not mean that the reverse is also true. Boosterish advertising, community propaganda or public relations are not effective or efficient ways to increase exports and bring in more tourists, investments and international students, because it abandons the customer focus logic of marketing products to target markets. Mass communication to broadcast community accomplishments to a global audience, as can be witnessed frequently on CNN or BBC World, is like shooting with hail to kill a fly. Without intricate targeting, the likelihood of reaching someone in the audience who is actually interested in absorbing what is being communicated is small indeed. Most media consumers will switch off or fail to comprehend why they are being "spoken to". Sure, beautiful cinematography might attract attention, but will it change people's 
minds? Not to mention the fact that using mass-media for marketing purposes makes it hard to control what type of tourist, investor or migrant worker one is attracting.

So while marketing can be effectively and efficiently applied to facilitate economic exchange of community offerings, it seems unsuitable when applied to communities as a whole. This is exactly where imaginative initiatives come in. These are projects and occasionally marketable products in their own right, yet they raise profile and reputation for the community. The Just Peace Festival in The Hague, Austin's South by Southwest (SXSW) Festival, Gaudí's creations as attractions in Barcelona or the resorts on Dubai's Palm Island are all commercial offerings as such. Yet, they have resulted in a raised profile and reputation for the communities involved, because they are compelling and uniquely local.

At the same time, other examples of imaginative initiatives are useful and meaningful in other ways-non-commercial, but still beneficial to the communities. Bhutan's focus on gross national happiness, Oslo's Future Library, or the Van Gogh-inspired "starry night" cycle path in the city of Eindhoven are all genuine projects or constructive policies that have a largely non-commercial local impact, while at the same time striking a chord with international audiences. In fact, if done well, imaginative initiatives do not require much marketing at all as they will promote themselves in today's social media landscape. While advertising pushes messages onto an unwilling audience, search and social media engagement provide opportunities for a willing audience to pull, enhance and share community experiences and stories that are of interest to self-selected audiences, sometimes facilitated by public diplomacy. These are exactly the kind of processes that imaginative communities exploit.

\section{How we re-brand}

So, the attentive reader might wonder, considering that imaginative initiatives are often marketable "products" that contribute to reputation, not unlike Simon Anholt's 'symbolic actions', is all this not branding? Assuming that indeed, branding is defined as the concerted effort to make something (products, services, corporations, communities, persons and so on) identifiably distinctive, in that case, yes, branding is the long-term strategic approach to building imaginative communities. Consistency in linking community identity with captivating initiatives will build brand equity for the community, as they become more recognisable and associated with positive perceptions.

The problem with the practice of applying branding concepts to communities, cities, regions and countries is that branding is often misinterpreted and the focus is put far too much on superficial aesthetics. In simple terms, branding is about two things: making something identifiable and making it distinctive. The first deals with naming and visual design, the second with meaning (brand positioning, personality, promise, etc.). The most important decision in commercial branding is, of course, naming, which is linked to trademarking. For communities, these kinds of decisions are almost completely irrelevant, as communities have (often long-established) names and those names are usually very hard to protect with a trademark. Yet many communities are still obsessed with consistency in presentation: type fonts, logos, use of colours or slogans. The question is whether that really matters.

Consistent presentation in commercial branding facilitates recognisability in advertising and retail environments, i.e. at the few touchpoints at which consumers engage with a brand. However, obviously, the retail environment is not where communities engage with audiences. Communities are abundantly represented, partly through public diplomacy, in mainstream news, social media and popular culture. Do logos and slogans, apart from the name, ever get noticed in these environments? There are so many more touchpoints and channels that communities deal with compared to corporations that it is hard to imagine that consistency in presentation has a real significant impact.

There are reasons why communities rightly spend resources on visual identity. Websites, stationery and business cards need to be designed and clever consistent representation does not hurt. This kind of design expertise, easily purchased, provides officials with prestige and pleasure, not to mention the peer pressure and one-upmanship that is experienced at international exhibitions, conferences, trade fairs and missions. However, what often seems to be forgotten is that trademarks (including logos) only become brands when they represent meaning to external audiences. So, if community branding is reduced to design, then no imaginative communities should largely ignore it. What successful imaginative communities do is to aim for long-term presence, positioning and purpose. To achieve that, visual identity is much, much less important than it is in commercial branding.

Yet, governments often wonder how they can enforce the use of their "brand" (they will say "brand" when they mean "logo") and regulate who can and who cannot carry it and in what way. It is the wrong question to ask and asking it is recognition of defeat. A good brand strategy not only builds engagement with the outside world, but also among stakeholders and internal audiences. It should be built on a sense of belonging and shared purpose and hence generate the kind of engagement that is desired and impossible to imitate elsewhere, motivating the internal stakeholders to contribute. This is how 'I $\mathcal{N Y}$ ' and 'I AMsterdam' became successful, not because they are clever design gimmicks (which they are), but because they represent something that 
people were already proud of or engaged with. Governments in New York City and Amsterdam did not need to strategise about what these logos were to represent and how to build awareness; the equity was already there in the minds of most people, both local stakeholders and global audiences. The logos just helped to create something to characterise that equity (i.e. a brand). Unfortunately, most communities do not have this luxury of a historically built global awareness and reputation and that is exactly why they want to "do something with branding", thinking that 'I $\bigcirc$...' will help them. It won't (many communities have specifically tried 'I -...' and failed). It is not the symbol that builds the reputation, but the symbol can become an icon for an existing reputation that has been painstakingly built over a period of time.

Another part of today's "misunderstanding of branding" is that everything is evaluated in economic terms, so even reputation is seen to be only of interest in as much as it facilitates marketing. At one time reputation was a legitimate goal in its own right, but this is no longer so much the case. Part of the reason is the loss of our religion, but globalisation may also be a factor, as most economic and political activities have become detached from local communities. Investors used to depend on their good name in their community for future business and/or a place in heaven. In today's world, where money is mobile, investors operate across borders and religion has lost its grip on society, reputation has become a means to an end, not an ethical question, but an economic one.

Unfortunately, a marketing approach to community branding (destination branding, investment branding, "made-in" branding) also does not work because of the way people build mental images. Reputations are indivisible networks of associations that people deploy whenever they engage with "the other". Usually, there is no single economic offering (a single tourist attraction, a specific export product or a unique investment offering) dominating the image, and where there is, it has proven to be unhealthy (resulting in over-tourism or economic vulnerabilities). Likewise, representation should also not be limited to specific economic sectors. It runs the risk of being too much demand driven as opposed to being about "who we are, where we came from and what we represent". Imaginative communities need to facilitate cooperation internally and externally, not focus on competition. The latter is the rhetoric of marketing and, unfortunately, more so than it should be, also that of branding.

The focus on competition and the market is counter-productive in community reputation management and hence my 2018 book advocates the idea of the imaginative community. Branding is its strategic perspective in building long-term presence, positioning and purpose. The brand concept is by no means obsolete when applied appropriately. It is about appreciating that the reputations and images of communities should - and understanding how they can-incorporate the sense of community and to formulate shared purpose and ideals based on the shared identity, formulating an aspirational strategic vision. Subsequently, it is about operationalising such a vision into a strategy that formulates policies, partnerships and actions that will enable the community to project an unbroken stream of imaginative community initiatives that will deliver the reputation it deserves.

\section{Research implications}

Even in 2019, this journal receives submissions in which place marketing, place branding and public diplomacy are used as interchangeable concepts. Sure, there is still no universal agreement about how to define these domains or how they relate to each other and the above attempt to provide some clarity, through the concept of imaginative communities, is just one interpretation (and I am well aware that others might hold different views). However, to submit a paper to this journal without clearly positioning it within the debate and to refer to the various concepts as though they are one and the same thing is unacceptable and a clear sign to the editors and reviewers that authors have little appreciation for and understanding of the specific body of knowledge that this journal contributes to and takes advantage of. Quite often, this ignorance seems to reflect opportunistic behaviour by authors from other fields of study who want to use our channels of publication by throwing in some relevant words and references so as to make their work seem relevant for the journal. In those cases, it is usually quickly picked up by the editors or reviewers and the papers rejected. However, this is not necessarily always the case and even emerging or junior domain-specific authors sometimes fail to clarify their position and use of concepts. Clearly, this needs to change.

The same is true for the usual opening sentence that competition between places for foreign investment, tourists, talent or trade has created a need for communities to market themselves, promote the country, sell the city. Is it really that simple? I think that by now, after 15 volumes of this journal, we have come to a point where we look more critically at these processes and their complexity. Competition happens in markets and projected and perceived images are part of the equation. Yet, branding and public diplomacy are not primarily about economics, so there must be more to it. We need more clarity on the theoretical framework for all this. The same is true for the often-stated assumption that there is a need for sectoral branding: destination branding, investment branding or "made-in" branding. I am not sure if we have corroborated this assumption or even that we really know what it means. Both in practice and research advertising has frequently been positioned as the magic solution for image problems. We have published quite a few 
communications impact studies, but usually with "clinical trials". I think there is a need for studies that demonstrate the medium- to long-term effects. At the same time, it would be of real interest to compare these findings to much needed image impact studies of imaginative initiatives or symbolic actions (to use Simon Anholt's terminology). Lastly, I think there is a serious gap in our understanding of the role that national or civic identity plays in place branding and public diplomacy. It is a highly contested, politicised and delicate discussion, but one that I think is crucial in the development of our field of study. We are certainly not done yet and there is work for at least 15 more years.

Publisher's Note Springer Nature remains neutral with regard to jurisdictional claims in published maps and institutional affiliations. 